\title{
Regional Trends in Mortality from Alcohol-Induced Causes in the United States, 2000-2017
}

\author{
George Cholankeril, MD ${ }^{1,2}$ (D) Brittany B. Dennis, MBBS, $P h D^{1,3}$, Donghee Kim, MD, $P h D^{7}$, \\ and Aijaz Ahmed, MD ${ }^{7}$
}

'Division of Gastroenterology and Hepatology,; Stanford University School of Medicine, Stanford, CA, USA; ${ }^{2}$ Department of Health Research and Policy, Division of Epidemiology ;:Stanford University School of Medicine, Stanford, CA, USA; ${ }^{3}$ Department of Medicine,;McMaster University, Hamilton, ON, Canada.

$J$ Gen Intern Med 35(8):2495-8

DOI: $10.1007 / \mathrm{s} 11606-019-05442-4$

(c) Society of General Internal Medicine 2019

\section{INTRODUCTION}

In the United States (US), alcohol use disorder remains a major contributor to all-cause morbidity with a persistent uptrend in deaths from alcohol-induced causes. ${ }^{1,}$

2 While recent guidelines from the US Preventative Services Task Force have recommended screening for all adults in the primary care setting, ${ }^{3}$ understanding the regional disparities and associated sociodemographic factors that may impact the mortality from alcoholinduced causes can aid in prioritizing allocation of resources to at-risk subpopulations.

\section{METHODS}

Using data obtained from the National Center for Health Statistics, we performed a cross-sectional study analyzing all deaths attributable to alcohol-induced causes as defined by the Center of Disease Control by US Census region (Northeast, Midwest, South, and West) and state from 2000 through $2017 .{ }^{4}$ Age-adjusted death rates (per 100,000 persons) for overall and population-specific cohorts were calculated for each US region and state using annual data from US Census

Received September 5, 2019

Revised September 5, 2019

Accepted September 26, 2019

Published online December 2, 2019
Bureau. ${ }^{4}$ The study period was divided into two periods, 2000-2009 and 2010-2017, and the relative percent change was calculated between these periods.

\section{RESULTS}

Overall, the age-adjusted mortality from alcohol-induced causes increased within all four US regions from 20002009 to 2010-2017, with similar rising trends in mortality from alcoholic liver disease (Table 1). The West region had the highest overall mortality from alcoholinduced causes; over a 75\% higher rate compared with all other US regions. From 2000 to 2009, the South had the second highest overall mortality but was surpassed by the Midwest in 2010-2017, with similar regional patterns noted in middle-aged adults between 45 and 64 years as well as both men and women.

Middle-aged adults (45-64 years) had the highest population-specific mortality and experienced at least a $20 \%$ relative increase across all 4 regions from 20002009 to 2010-2017. Although men and women also experienced increases in mortality, these death rates remained more than twofold higher in men in each region. Based on race/ethnicity, non-Hispanic Whites experienced the largest relative change in mortality in all four regions from 2000-2009 to 2010-2017 and surpassed mortality in non-Hispanic Blacks in the Northeast, Midwest, and South from 2000-2009 to 2010-2017. Non-Hispanic Blacks were the only sociodemographic subgroup that experienced a decline in mortality. Although mortality among Hispanics remained relatively unchanged, mortality among Hispanics in the West surpassed that of all other race/ ethnicities in any region. 
Table 1 Age- and Population-Specific Adjusted Death Rates (Per 100,000 Persons) Attributed to Alcohol-Induced Causes Within the 4 United States Regions from 2000 to 2017

\begin{tabular}{|c|c|c|c|c|}
\hline $\begin{array}{l}\text { Sociodemographic } \\
\text { characteristic }\end{array}$ & $\begin{array}{l}\text { Northeast } \\
(95 \% \text { CI) }\end{array}$ & $\begin{array}{l}\text { Midwest } \\
\text { (95\% CI) }\end{array}$ & $\begin{array}{l}\text { South } \\
\text { (95\% CI) }\end{array}$ & $\begin{array}{l}\text { West } \\
(95 \% \text { CI) }\end{array}$ \\
\hline Total & $5.8(5.8-5.9)$ & $6.9(6.9-7.0)$ & $6.9(6.9-6.9)$ & $11.9(11.8-12.0)$ \\
\hline 2000-2009 & $5.7(5.6-5.7)$ & $6.3(6.2-6.3)$ & $6.7(6.6-6.7)$ & $10.9(10.9-11.0)$ \\
\hline 2010-2017 & $7.5(7.4-7.6)$ & $8.9(8.8-9.0)$ & $8.3(8.2-8.4)$ & $13.9(13.8-14.0)$ \\
\hline$\%$ change & 31.5 & 41.2 & 23.8 & 12.9 \\
\hline \multicolumn{5}{|l|}{ Age groups (years) } \\
\hline $45-64$ & $15.3(15.1-15.4)$ & $18.3(18.1-18.4)$ & $18.9(18.8-19.0$ & $30.6(30.4-30.8)$ \\
\hline $2000-2009$ & $13.5(13.3-13.7)$ & $15.3(15.1-15.5)$ & $17.1(16.9-17.2)$ & $27.6(27.3-27.8)$ \\
\hline $2010-2017$ & $17.2(17.0-17.5)$ & $21.5(21.3-21.8)$ & $20.9(20.7-21.0)$ & $33.8(33.5-34.0)$ \\
\hline$\%$ change & 27.4 & 40.5 & 22.2 & 22.5 \\
\hline$\geq 65$ & $9.3(9.2-9.5)$ & $10.5(10.3-10.6)$ & $11.2(11.1-11.3)$ & $22.0(21.8-22.3)$ \\
\hline $2000-2009$ & $8.4(8.2-8.7)$ & $9.4(9.2-9.6)$ & $10.3(10.2-10.5)$ & $20.8(20.5-21.1)$ \\
\hline $2010-2017$ & $10.3(10.1-10.6)$ & $11.6(11.4-11.9)$ & $12.0(11.8-12.2)$ & $23.2(22.9-23.6)$ \\
\hline$\%$ change & 22.6 & 23.4 & 16.5 & 11.5 \\
\hline \multicolumn{5}{|l|}{ Gender } \\
\hline Women & $2.9(2.8-2.9)$ & $3.6(3.5-3.6)$ & $3.3(3.3-3.3)$ & $6.5(6.4-6.5)$ \\
\hline $2000-2009$ & $2.3(2.1-2.5)$ & $2.6(2.4-2.7)$ & $3.0(2.9-3.2)$ & $5.0(4.8-5.3)$ \\
\hline 2010-2017 & $3.3(3.2-3.4)$ & $4.3(4.2-4.3)$ & $3.7(3.7-3.8)$ & $7.3(7.3-7.4)$ \\
\hline$\%$ change & 43.4 & 65.4 & 23.3 & 46.0 \\
\hline Men & $9.1(9.0-9.2)$ & $10.6(10.5-10.6)$ & $10.9(10.9-11.0)$ & $17.7(17.6-17.8)$ \\
\hline $2000-2009$ & $8.4(8.3-8.5)$ & $9.4(9.3-9.5)$ & $10.4(10.3-10.5)$ & $16.7(16.6-16.9)$ \\
\hline $2010-2017$ & $9.9(9.8-10.0)$ & $11.8(11.7-11.9)$ & $11.4(11.3-11.5)$ & $18.7(18.5-18.8)$ \\
\hline$\%$ change & 17.9 & 25.5 & 9.6 & 12.0 \\
\hline \multicolumn{5}{|l|}{ Race/ethnicity } \\
\hline Non-Hispanic White & $5.9(5.8-5.9)$ & $6.8(6.8-6.9)$ & $7.5(7.4-7.5)$ & $12.0(11.9-12.1)$ \\
\hline $2000-2009$ & $5.1(5.0-5.2)$ & $5.8(5.8-5.9)$ & $6.6(6.5-6.6)$ & $10.8(10.7-10.9)$ \\
\hline $2010-2017$ & $6.7(6.7-6.8)$ & $8.0(7.9-8.1)$ & $8.4(8.4-8.5)$ & $13.3(13.2-13.4)$ \\
\hline$\%$ change & 31.3 & 37.9 & 27.3 & 23.1 \\
\hline Non-Hispanic Black & $6.2(6.0-6.3)$ & $7.4(7.2-7.5)$ & $6.3(6.2-6.4)$ & $10.2(10.0-10.5)$ \\
\hline $2000-2009$ & $6.3(6.1-6.5)$ & $7.3(7.1-7.5)$ & $6.9(6.8-7.0)$ & $10.3(9.9-10.7)$ \\
\hline 2010-2017 & $6.0(5.8-6.2)$ & $7.5(7.2-7.7)$ & $5.6(5.5-5.7)$ & $10.2(9.8-10.5)$ \\
\hline$\%$ change & -4.8 & 2.7 & -18.8 & -0.1 \\
\hline Hispanic or Latino & $7.0(6.8-7.2)$ & $6.6(6.4-6.9)$ & $5.8(5.7-5.9)$ & $14.2(14.0-14.4)$ \\
\hline $2000-2009$ & $7.0(6.7-7.2)$ & $5.7(5.4-6.1)$ & $5.7(5.6-5.9)$ & $14.1(13.9-14.4)$ \\
\hline 2010-2017 & $7.0(6.8-7.3)$ & $7.3(7.0-7.7)$ & $5.9(5.8-6.1)$ & $14.2(14.0-14.4)$ \\
\hline$\%$ change & - & 28.1 & 3.5 & 0.7 \\
\hline Alcoholic liver disease & $3.2(3.1-3.2)$ & $4.1(4.0-4.1)$ & $4.2(4.1-4.2)$ & $7.9(7.9-8.0)$ \\
\hline $2000-2009$ & $2.9(2.8-2.9)$ & $3.5(3.5-3.6)$ & $3.8(3.7-3.8)$ & $7.2(7.2-7.3)$ \\
\hline $2010-2017$ & $3.5(3.4-3.5)$ & $4.7(4.7-4.8)$ & $4.6(4.5-4.6)$ & $8.6(8.6-8.7)$ \\
\hline$\%$ change & 15.4 & 34.3 & 21.1 & 19.4 \\
\hline
\end{tabular}

Causes of death attributable to alcohol-induced mortality included the following ICD-10 codes: E24.4, alcohol-induced pseudo-Cushing's syndrome; F10, mental and behavioral disorders due to alcohol use; G31.2, degeneration of the nervous system due to alcohol; G62.1, alcoholic polyneuropathy; G72.1, alcoholic myopathy; I42.6, alcoholic cardiomyopathy; K29.2, alcoholic gastritis; K70, alcoholic liver disease; K85.2, alcohol-induced acute pancreatitis; K86.0, alcohol-induced chronic pancreatitis; R78.0, finding of alcohol in blood; X45, accidental poisoning by and exposure to alcohol; X65, intentional self-poisoning by and exposure to alcohol; and Y15, poisoning by and exposure to alcohol, undetermined intent. Alcohol-induced causes excluded unintentional injuries, homicides, and other causes indirectly

State-specific mortality from alcohol-induced causes in 2000-2009 and 2010-2017 is depicted in Fig. 1. All states except Alaska and Maryland experienced an increase in mortality. From 2000 to 2009 , only two states, Alaska (19.7) and New Mexico (18.6), had a mortality surpassing 15 deaths per 100,000 persons. However, from 2010 to 2017 , this number increased to seven states, all from the Southwest and Northwest sections of the West region including New Mexico (25.2), Alaska (18.7), Wyoming (18.3), Arizona (16.0), Oregon (16.0), South Dakota (15.9), and Montana (15.5). Moreover, $32 \%$ (16) of US states had mortality surpassing 10 deaths per 100,000 persons from 2010 to 2017.

\section{DISCUSSION}

Mortality from alcohol-induced causes increased in all four regions of the US with highest rates in the West-largely attributed to states in the Southwest (Arizona and New Mexico) and Northwest (Wyoming, Oregon, and Montana). More importantly, while these data highlight the ongoing regional increase in mortality in nearly all sociodemographic groups; middle-aged adults, men, and non-Hispanic Whites in all regions as well as Hispanics in the West were seemingly at highest risk. These ominous trends warrant a comprehensive plan by the policy makers in the federal government in conjunction with a targeted approach by stake holders at the state level. These data may help health care providers on a regional/ state level to focus on preemptive screening, counselling, and 
a Age-adjusted Death Rate

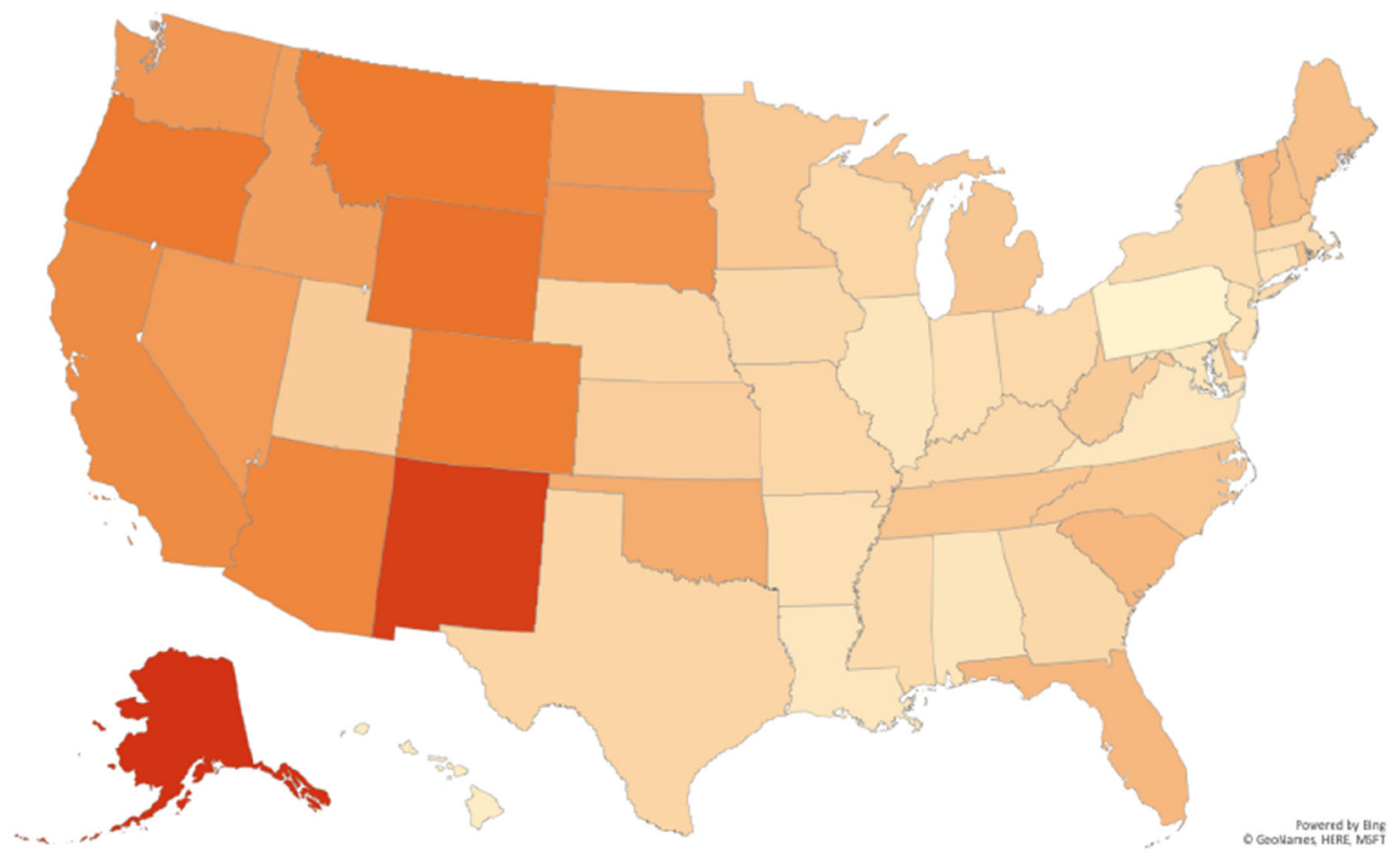

b
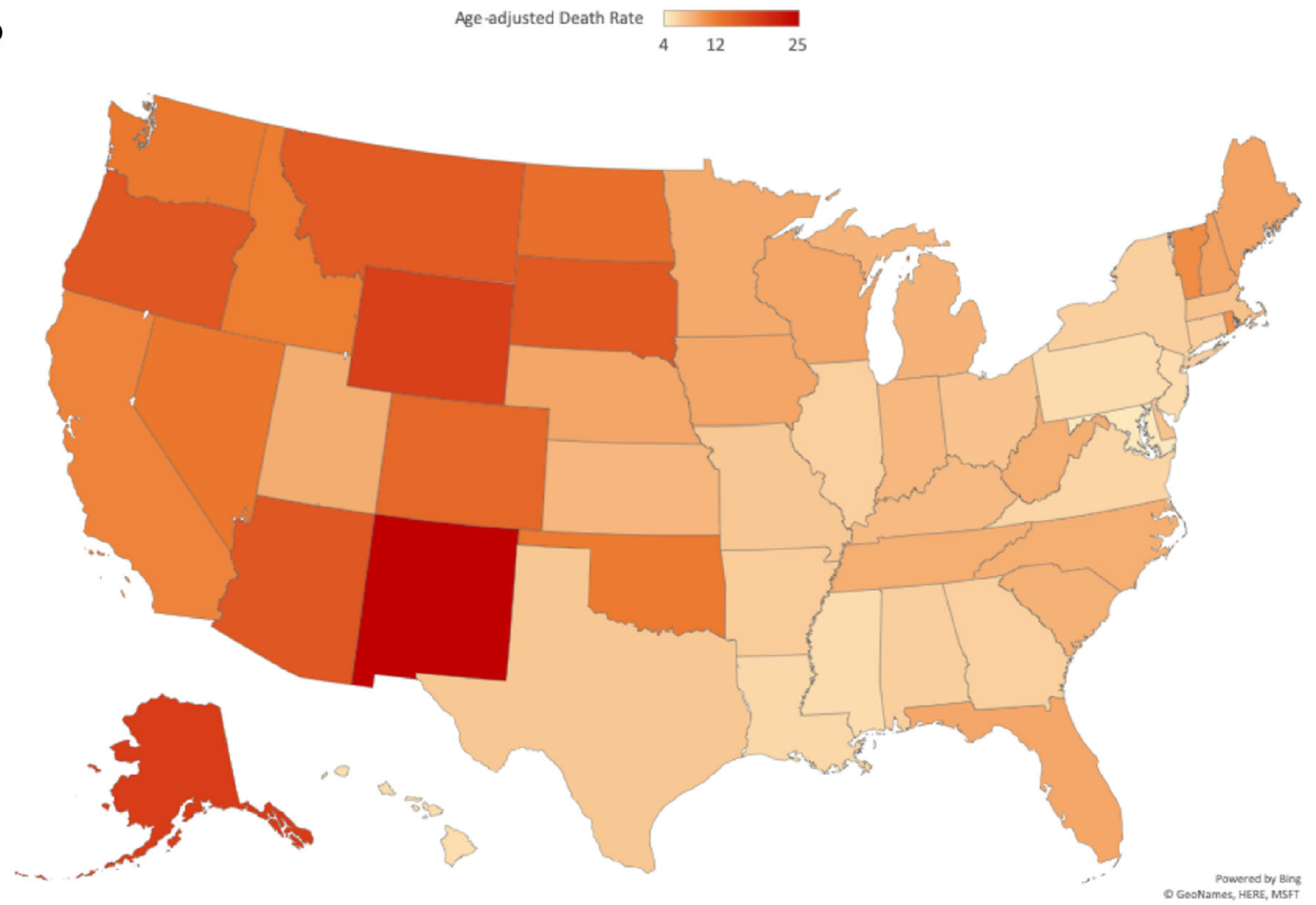

Figure 1 Comparison of state-specific mortality rates from alcohol-induced causes in the United States from 2000 through 2009 and 2010 through 2017. a Age-adjusted mortality rate from alcohol-induced causes in the United States by state from 2000 through 2009 . b Age-adjusted mortality rate from alcohol-induced causes in the United States by state from 2010 through 2017. 
intervention in the primary care setting among at-risk subpopulations.

Corresponding Author: George Cholankeril, MD; Division of Gastroenterology and Hepatology Stanford University School of Medicine, Stanford, CA, USA (e-mail: georgetc@stanford.edu).

Author Contributions Dr. Cholankeril was involved in study concept and design, analysis and interpretation of data, drafting of the manuscript, critical revision of the manuscript for important intellectual content, and study supervision. Dr. Dennis, Dr. Kim, and Dr: Ahmed were involved in interpretation of data, drafting of the manuscript, and critical revision of the manuscript for important intellectual content.

Funding Information Dr. Cholankeril is supported by NIH Training Grant T32DK007056. None of the authors received financial or material support for the research and work in this manuscript.

Data Availability All data including statistical code used to generate results and the dataset from which the results were derived will be made available upon request to the corresponding author.

\section{Compliance with Ethical Standards:}

Conflict of Interest: The authors declare that they do not have a conflict of interest.

\section{REFERENCES}

1. Grant BF, Chou SP, Saha TD, et al. Prevalence of 12-Month Alcohol Use, High-Risk Drinking, and DSM-IV Alcohol Use Disorder in the United States, 2001-2002 to 2012-2013: Results From the National Epidemiologic Survey on Alcohol and Related Conditions. JAMA Psychiatry 2017;74(9):911-923.

2. Kim D, Li AA, Gadiparthi C, et al. Changing Trends in Etiology-Based Annual Mortality From Chronic Liver Disease, From 2007 Through 2016. Gastroenterology. 2018;155(4):1154-1163 e1153.

3. Curry SJ, Krist AH, et al. Screening and Behavioral Counseling Interventions to Reduce Unhealthy Alcohol Use in Adolescents and Adults: US Preventive Services Task Force Recommendation Statement. JAMA. 2018;320(18):1899-1909.

4. Centers for Disease Control and Prevention, National Center for Health Statistics. Underlying Cause of Death 1999-2017 on CDC WONDER Online Database, released December 2018. Data are from the Multiple Cause of Death Files, 1999-2017, as compiled from data provided by the 57 vital statistics jurisdictions through the Vital Statistics Cooperative Program. Accessed at http://wonder.cdc.gov/ucd-icd10.html on Jul 25, 2019.

Publisher's Note Springer Nature remains neutral with regard to jurisdictional claims in published maps and institutional affiliations. 